This item was submitted to Loughborough's Research Repository by the author.

Items in Figshare are protected by copyright, with all rights reserved, unless otherwise indicated.

\title{
Fast determination of moment of inertia of permanent magnet synchronous machine drives for design of speed loop regulator
}

\section{PLEASE CITE THE PUBLISHED VERSION}

http://dx.doi.org/10.1109/TCST.2016.2615090

PUBLISHER

IEEE Control Systems Society

VERSION

AM (Accepted Manuscript)

LICENCE

CC BY-NC-ND 4.0

\section{REPOSITORY RECORD}

Liu, Kan, and Zi-Qiang Zhu. 2019. "Fast Determination of Moment of Inertia of Permanent Magnet Synchronous Machine Drives for Design of Speed Loop Regulator". figshare.

https://hdl.handle.net/2134/22663. 


\title{
Fast Determination of Moment of Inertia of Permanent Magnet Synchronous Machine Drives for Design of Speed Loop Regulator
}

\author{
Kan Liu, IEEE Member, and Z.Q. Zhu, Fellow, IEEE
}

\begin{abstract}
This paper proposes a novel method for the fast determination of moment of inertia of permanent magnet synchronous machine (PMSM) drive systems. It is based on the use of sinusoidal perturbation signals and can determine the combined moment of inertia within one sinusoidal cycle of perturbation while the influence of viscous friction is eliminated during the modeling process. It does not need the aid of complex system identification algorithms, and thanks to the elimination of influence of viscous friction, the proposed scheme shows higher accuracy than the conventional method without taking into account. Furthermore, its accuracy is also competitive with the conventional method using complex system identification algorithms, for example, the model reference adaptive system (MRAS). Besides, the performance of designed speed regulators using the estimated mechanical parameters and the influence of mismatching of mechanical parameters are also investigated.
\end{abstract}

Index Terms-Electrical machine drive, mechanical parameter, moment of inertia, parameter determination, permanent magnet synchronous machine, viscous friction coefficient

\section{INTRODUCTION}

$\mathrm{P}$ arameters of permanent magnet synchronous machine (PMSM) drive systems are of great importance for the design of controllers and related parameter determination technologies are now widely reported [1]-[28]. For example, electrical parameters such as $d q$-axis inductances and winding resistance [20] are usually needed for the design of current loop proportional-integral (PI) controllers while mechanical parameters such as combined moment of inertia $(J)$ and viscous friction coefficient $(F)$ are quite important for the design of speed loop controllers [18]-[20], [22]-[25]. In reality, electrical parameters will not vary too much and the designed current loop PI regulators are usually robust to the varying working points. However, mechanical parameters usually vary significantly with the dimensions and the shape of mechanical loads. For example, it is quite normal in some direct-drive applications that the moment of inertia of mechanical load, such as the wind turbine blade, the rigid cylinder of printing press, and the actuator of loom, is usually more than 10 times larger than that of PMSM rotor. Besides, in those applications

Manuscript received Feb 29, 2016; revised July 7, 2016; accepted September 20, 2016. Recommended by Dr. Aranya Chakrabortty.

$\mathrm{K}$. Liu is currently with the Control Systems Research group, Loughborough and was with the Electrical Machines and Drives Research Group, University of Sheffield (e-mail: k.liu3@lboro.ac.uk).Z.Q. Zhu is with the Electrical Machines and Drives Research Group, University of Sheffield, UK (e-mail: Z.Q.Zhu@sheffield.ac.uk). with gear boxes between the machine and the load, the reflected inertia of the load may be quite high. In this case, a mismatched machine may not be powerful enough to ensure the dynamic performance of the drive system. Therefore, most servo drives have an upper limit to the ratio of load inertia versus rotor inertia. For example, the upper limit of the ratio of load inertia versus rotor inertia of a Panasonic MINAS A4 Series servo drive is 100 . Besides, for the high frequency injection based sensorless control of low speed PMSM [26], [27], the correlation between the load inertia and the frequency/ amplitude of injected current also needs to be considered during the controller design [26].

Thus, for a commercial drive, it is required that the software should have the ability to determine the mechanical parameters of the whole drive train, especially the combined moment of inertia. Existing methods for the determination of mechanical parameters of drive systems can be mainly categorized into three types, which are reviewed as follows.

The first type is based on the addition of periodic perturbations in electromagnetic torque or rotor speed, by which the transient torque due to the moment of inertia will not be zero but a forward-reverse variable with respect to the time [1]-[7]. This type of solution is easy for implementation and also widely reported in the application of different machines such as DC machine [6], [15], induction machine (IM) [1], [2] and PMSM [3]-[8]. This type of method usually uses system identification algorithms such as model reference adaptive system (MRAS) [7], [16], [17], extended Kalman filter [8], and recursive least square (RLS) [2] to online or offline estimate parameters from measured data.

The second type calculates the moment of inertia during the startup of electric machines or the step response of drive systems. Similar to that of the first type, the transient torque due to the moment of inertia will not be zero but a constant (for a constant acceleration or deceleration) or a variable term (for a variable acceleration or deceleration) [10], [11].

The third type usually works at the loaded condition and regards the mechanical load as a constant disturbance torque [1], [3], [6], [11]-[14]. For example, in [1], system inertia and disturbance torque are estimated to aid the speed observation of a low speed induction machine. In [28], the RLS is employed for the estimation of variations of time-varying inertia and load torque, which are then employed to improve the performance of a back stepping controller for low speed PMSM.

In this paper, a method for fast determination of the combined moment of inertia of the PMSM drive system is proposed, which is based on the addition of zero mean 
sinusoidal perturbation to the drive system. It can estimate the combined moment of inertia within one sinusoidal cycle of perturbation and does not need the aid of complex system identification algorithms while the influence of viscous friction is eliminated during the modeling process. Besides, a comparison with two conventional methods is conducted and the application of estimated mechanical parameters to the design of speed loop PI regulator is also investigated.

\section{Conventional AND Proposed Estimation Schemes}

In the drive control, the PMSM can be expressed in the $d q$-axis reference frame as follows:

$u_{d}=R i_{d}-L_{q} \omega i_{q}+L_{d} \frac{d i_{d}}{d t}$

$u_{q}=R i_{q}+L_{d} \omega i_{d}+\psi_{m} \omega+L_{q} \frac{d i_{q}}{d t}$

$T_{e}=1.5 p\left[\psi_{m} i_{q}+\left(L_{d}-L_{q}\right) i_{d} i_{q}\right]=1.5 p K_{e} i_{q}$

$J \frac{d \omega_{r}}{d t}=T_{e}-F \omega_{r}-T_{m}$

where $\psi_{m}, R, L_{d}, L_{q}, i_{d}, i_{q}, \omega, u_{d}, u_{q}, p, K_{e}, J, F, \omega_{r}, T_{e}$ and $T_{m}$ are rotor PM flux linkage, winding resistance, $d q$-axis inductances, $d q$-axis currents and voltages, electrical angular speed, pole pair number, torque constant, combined moment of inertia, viscous friction coefficient, mechanical angular speed, electromagnetic torque, and disturbance torque, respectively. In (1), terms such as $R i_{d}, R i_{q}, \psi_{m} \omega, L_{d} \omega i_{d}$ and $-L_{q} \omega i_{q}$ and are voltage drops due to winding resistance, PM flux linkage, and $d q$-axis inductances. It is noteworthy that the $q$-axis flux linkage $L_{q} i_{q}$ is perpendicular to the $d$-axis while its resulting voltage $L_{q} \omega i_{q}$ is in the negative direction of $d$-axis. In reality, $T_{m}$ can be produced by an excited machine, a spring [28], gravity [5] and other external forces. Besides, it should be emphasized that for simplicity, the parameter $F$ in this paper can be regarded as a lumped parameter representing all nonlinear terms such as viscous/Coulomb friction, core loss and windage effects.

\section{A. Conventional Scheme1}

It is proposed in [21] that $J$ can be derived by an acceleration or deceleration process if the influence of $F \omega_{r}$ can be ignored. As shown in Fig. 1(a), the open loop transfer function of the mechanical model of PMSM drive is a first order system and the gain of the input signal is $1.5 p K_{e}$. On condition that the influence of $F \omega_{r}$ is negligible, it can be simplified to an integral element and the gain of the input signal is $\frac{1.5 p K_{e}}{J}$, as depicted in Fig. 1(b). For a discrete sampling system, the output of an integral element during the unit step response at the $n$-th sampling time point can be expressed as $t=T=n T_{s}$, in which $T_{s}$ is the sampling time. Thus, on condition that the influence of $F \omega_{r}$ can be ignored, $J$ can be approximately calculated by (2) [21] and this scheme is designated as Scheme1 in this paper.

$$
J=\frac{1.5 p K_{e} \sum_{n}^{n=N} i_{q}\left(t=n T_{s}\right) n T_{s}}{\sum_{n}^{n=N} \omega_{r}\left(t=n T_{s}\right)}
$$

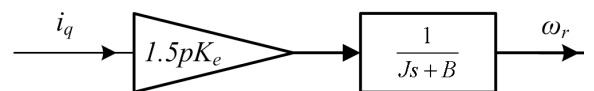

(a)

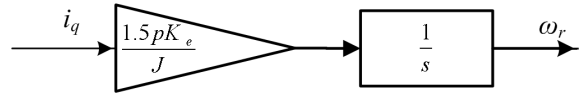

(b)

Fig. 1. Transfer function of mechanical model of PMSM. (a) and (b) Transfer functions taking into account and ignoring influence of $F$.

\section{B. Conventional Scheme2}

As detailed hereinbefore, observers based methods such as MRAS, RLS, and EKF are widely used for the estimation of mechanical parameters. By way of example, the conventional MRAS observer is selected and introduced, which is designated as Scheme 2 in this paper. Assuming that $\widetilde{\omega}_{r}, \widetilde{J}$, and $\widetilde{F}$ are the estimated $\omega_{r}, J$ and $F$, respectively, the MRAS observer will usually be expressed in the form of PI controllers [16], [17]:

$$
\begin{aligned}
& \widetilde{J}=\frac{1}{\frac{1}{J_{0}}+P_{J}\left(e T_{e}\right)+I_{J} \int e T_{e} d t} \\
& \widetilde{F}=\widetilde{J}\left(\frac{F_{0}}{J_{0}}-P_{F}\left(e \tilde{\omega}_{r}\right)-I_{F} \int e \tilde{\omega}_{r} d t\right)
\end{aligned}
$$

where $e=\omega_{r}-\widetilde{\omega}_{r}$ and $P_{J}, I_{J}, P_{F}, I_{F}, J_{0}$ and $F_{0}$ are PI constants of MRAS observers of $J$ and $F$, and initial values of estimated $J$ and $F$, respectively.

\section{Proposed Method (Scheme3)}

In order to eliminate the influence of $F \omega_{r}$, a novel method is proposed and designated as Scheme3. Assuming that the $d q$-axis currents are set to $i_{d}=0$ and $i_{q}=i_{q p}{ }^{*} \sin \left(\omega_{h} t\right)$, respectively, in which $\omega_{h}$ and $i_{q p}{ }^{*}$ are the frequency and amplitude of injected $i_{q}$. The resulting $\omega_{r}$ can be expressed as $\omega_{r}=\omega_{p} \sin \left(\omega_{h} t+\varphi\right)$, in which $\omega_{p}$ is the peak value of $\omega_{r}$ and $\varphi$ is the phase shift between $i_{q}$ and $\omega_{r}$. Thus, on condition that the disturbance torque is set to zero, $T_{m}=0$, (1d) can be transformed to:

$$
\begin{aligned}
& J \frac{d\left(\omega_{p} \sin \left(\omega_{h} t+\varphi\right)\right)}{d t}=1.5 p \psi_{m} i_{q p}{ }^{*} \sin \left(\omega_{h} t\right)-F \omega_{p} \sin \left(\omega_{h} t+\varphi\right) \\
& J \omega_{p} \omega_{h} \cos \left(\omega_{h} t+\varphi\right) \\
& =1.5 p \psi_{m} i_{q p}{ }^{*} \sin \left(\omega_{h} t\right)-F \omega_{p} \sin \left(\omega_{h} t+\varphi\right)
\end{aligned}
$$

At the transient of zero crossing $\left(t=t_{0}\right)$ of rotor speed, $\omega_{r}\left(t=t_{0}\right)=\omega_{p} \sin \left(\omega_{h} t_{0}+\varphi\right)=0$ and $\cos \left(\omega_{h} t_{0}+\varphi\right)=1$. Thus, the torque component owing to $F \omega_{r}$ will also be zero at this time point $\left(t=t_{0}\right)$ and (5) can be simplified to:

$$
J \omega_{p} \omega_{h}=1.5 p \psi_{m} i_{q p}{ }^{*} \sin \left(\omega_{h} t_{0}\right)=1.5 p \psi_{m} i_{q}\left(t=t_{0}\right)
$$

Thus, $J$ can be calculated by:

$J=\frac{1.5 p \psi_{m} i_{q p}{ }^{*} \sin \left(\omega_{h} t_{0}\right)}{\omega_{p} \omega_{h}}=\frac{1.5 p \psi_{m} i_{q}\left(t=t_{0}\right)}{\omega_{p} \omega_{h}}$

As can be seen from (7), only $i_{q}\left(t=t_{0}\right)$ and $\omega_{p}$ are needed for the derivation of $J$ and compared with the Scheme2, it does not need to differentiate the rotor speed. Thus, the proposed Scheme3 will be of lower computational cost compared with those conventional observer algorithm based estimation schemes. For the sake of better understanding, the flow chart of the proposed determination of $J$ is illustrated in Fig. 2: 


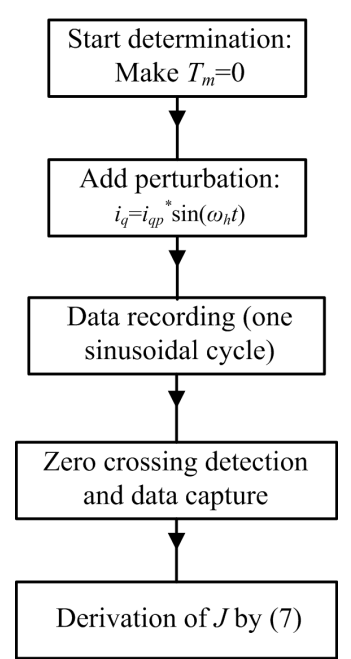

Fig. 2. Flow chart for determination of combined moment of inertia by Scheme3.

Step1. Set the disturbance torque to zero $\left(T_{m}=0\right)$.

Step2. Add the sinusoidal perturbation signal $i_{q}=i_{q p}{ }^{*} \sin \left(\omega_{h} t\right)$.

Step3. One sinusoidal cycle of machine data such as rotor speed and $d q$-axis currents will be recorded.

Step4. The time point of zero crossing of rotor speed will be indexed from the recorded data by using the program introduced in Appendix A, by which the value of $i_{q}\left(t=t_{0}\right)$ can be directly obtained. Besides, the value of $\omega_{p}$ can be indexed by shifting a quarter of one sinusoidal cycle.

Step5. With the aid of obtained $i_{q}\left(t=t_{0}\right)$ and $\omega_{p}$, the combined moment of inertia can be derived from (7).

Similarly, at the peak value of rotor speed $\left(t=t_{p}\right)$, $\sin \left(\omega_{h} t_{p}+\varphi\right)=1$ and $\cos \left(\omega_{h} t_{p}+\varphi\right)=0$, which yields:

$$
F \omega_{p}=1.5 p \psi_{m} i_{q p}{ }^{*} \sin \left(\omega_{h} t_{p}\right)=1.5 p \psi_{m} i_{q}\left(t=t_{p}\right)
$$

As can be seen from (8), $F$ at the peak value of rotor speed can be derived as:

$$
F=\frac{1.5 p \psi_{m} i_{q}\left(t=t_{p}\right)}{\omega_{p}}
$$

However, the result of (9) is the transient value of $F$, which is only related to the transient rotor speed. In order to obtain the exact correlation between $F$ and rotor speed, a steady state test will be preferred [17] in real applications. At the steady state of $T_{m}=0$, (1d) is simplified to $T_{e} \approx F \omega_{r}$ and $F$ can be obtained by:

$F \approx \frac{\operatorname{mean}\left(T_{e}\right)}{\operatorname{mean}\left(\omega_{r}\right)}=\frac{\operatorname{mean}\left(1.5 p K_{e} i_{q}\right)}{\operatorname{mean}\left(\omega_{r}\right)}$

where 'mean' is the mean operator. Thus, the variation of $F$ with respect to different rotor speeds can be therefore obtained. The operation process for the determination of $F$ with respect to different rotor speeds consists of three steps:

Step1. Set the disturbance torque to zero $\left(T_{m}=0\right)$.

Step2. Set the rotor speed to different values ranging from low to rated rotor speeds.

Step3. At the steady state of each point of rotor speed, $F$ will be calculated by (10).

In order to evaluate the performance of the proposed Scheme3, a comparison with the other two conventional schemes (Scheme1 and Scheme2) is conducted in next section.

\section{EXPERIMENTAL VALIDATION AND INVESTIGATION}

The prototype PMSM together with the load DC machine and drive system is depicted in Fig. 3. The design parameters are listed in Table I, in which the moment of inertia of rotor and couplings are calculated by using their mechanical dimensions and material density. Besides, a dSPACE 1006 based field oriented drive is employed to feed the PMSM and the sampling rate is set to $2 \mathrm{kHz}$. The block diagram of vector control system is depicted in Fig. 3(b). For the determination of $J$, the speed loop regulator will be removed by switching off $K$ and the $d q$-axis reference currents will be setup by software. The calculated $J$ of rotor of DC load machine is about $6.70 \times 10^{-3}$ $\mathrm{kg} . \mathrm{m}^{2}$ and the overall combined moment of inertia of the whole drive system is $6.70 \times 10^{-3}+4 \times 2.42 \times 10^{-4}+2.66 \times 10^{-5}+3.61 \times 10^{-4}$ $\approx 8.06 \times 10^{-3} \mathrm{~kg} \cdot \mathrm{m}^{2}$. In this paper, $T_{m}=0$ if the DC load machine is open-circuit or the DC load machine is removed.

In order to test the accuracy of the three methods introduced in Section II, three load conditions will be investigated:

C1: There is no mechanical load and only $J$ of bare rotor is estimated or calculated.

$\mathrm{C} 2$ : One side of the coupling is mounted on the rotor shaft.

C3: The DC load machine is connected with the PMSM.

\section{A. Comparison between Scheme1 and Scheme3}

The performance of Scheme1 is experimentally investigated at $\mathrm{C} 1, \mathrm{C} 2$ and $\mathrm{C} 3$, respectively, and the results are compared in Table II. For simplicity, the nominal value of rotor PM flux linkage shown in Table I will be employed for the calculation of electromagnetic torque although it is reported in [17] that the saturation of machine parameters will influence on the accuracy of estimation of mechanical parameters. An example of the step response of PMSM rotor speed is shown in Fig. 4 and aiming to achieve the fast determination of $J$ by (2), the data length $N=400$ is employed, which corresponds to $0.2 \mathrm{~s}$ of sampling. As can be seen from Table II, the accuracy of Scheme 1 will be quite low if $J$ is quite small, for example, at $\mathrm{C} 1$ and $\mathrm{C} 2$. This can be explained that the influence of static friction and $F \omega_{r}$ is not negligible at $\mathrm{C} 1$ and $\mathrm{C} 2$. In order to investigate their influences, a comparison between the simulated and experimentally measured step responses of rotor speeds is now given in Fig. 4. In the simulation model, the variation of $F$ with respect to $\omega_{r}$ at $\mathrm{C} 1, \mathrm{C} 2$, and $\mathrm{C} 3$, is approximated by a linear function as introduced in Appendix B, while $J$ is set to its nominal value as shown in Table I. With the calculated $F\left(\omega_{r}\right)=a x+b$ and nominal value of $J$, the simulated step response of rotor speeds at $\mathrm{C} 1$ and $\mathrm{C} 2$, respectively, is shown in Fig. 4(b). It is found that at the beginning of step response, the slope of simulated rotor speed is relatively higher than that of experimental results. This can be explained that the electromagnetic torques at $\mathrm{C} 1$ and $\mathrm{C} 2$ are relatively small $\left(i_{q}=0.1 \mathrm{~A}\right)$ and the static friction will slow down the speed of step response which is not modeled in the simulation model. Besides, during the step response at C3 $\left(i_{q}=1\right.$, with DC load machine), the rotor speed will be limited to around 400rpm due to the limit of DC bus voltage, as shown in Fig. 4(a). Since there is no limit to the rotor speed and DC bus voltage in the simulation model, the simulated rotor speed will continue increasing even if it is higher than 400rpm. 


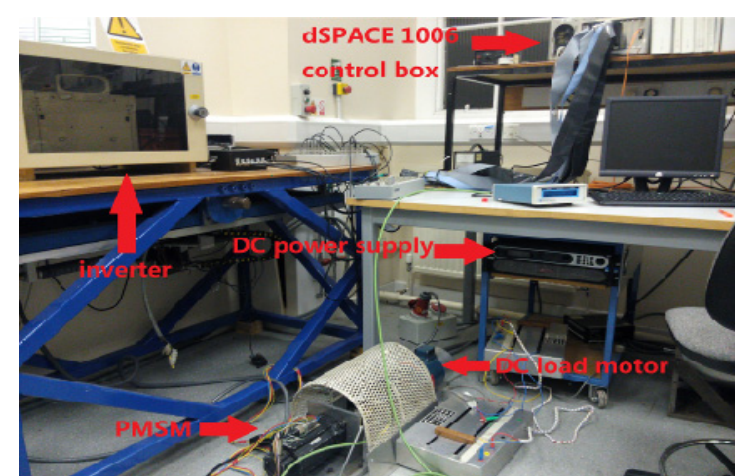

(a)

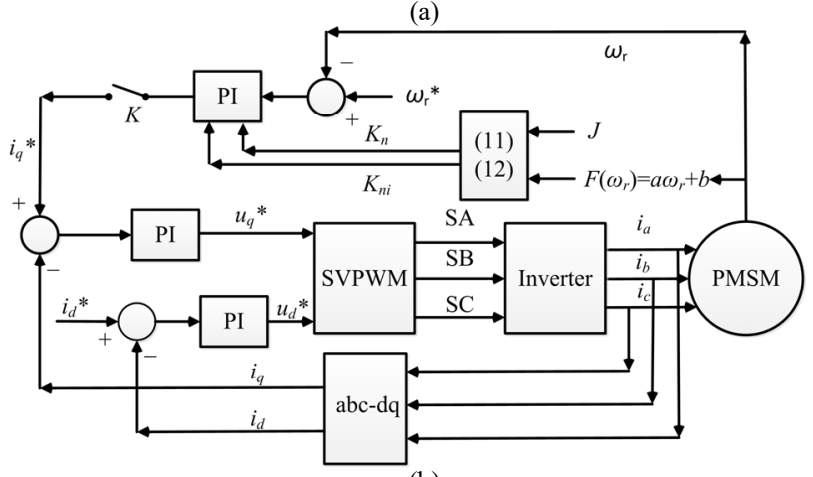

(b)

Fig. 3 Machine test system. (a) PMSM, load DC machine and dSPACE drive system. (b) Block diagram of control system.

TABLE I

DESIGN PARAMETERS AND SPECIFICATION OF PMSM

\begin{tabular}{ll}
\hline Parameters & Value \\
\hline Rated current & $4 \mathrm{~A}$ \\
Rated speed & $400 \mathrm{rpm}$ \\
DC link voltage & $100 \mathrm{~V}$ \\
Nominal phase resistance & $6.000 \Omega$ \\
Nominal $d$-axis inductances & $38.10 \mathrm{mH}$ \\
Nominal $q$-axis inductances & $58.50 \mathrm{mH}$ \\
Nominal rotor PM flux linkage & $236.0 \mathrm{mWb}$ \\
Number of pole pairs & 3 \\
Nominal moment of inertia of rotor & $3.61 \times 10^{-4} \mathrm{~kg} \cdot \mathrm{m}^{2}$ \\
Nominal value of moment of inertia of rotor coupling & $2.42 \times 10^{-4} \mathrm{~kg} \cdot \mathrm{m}^{2}$ \\
Moment of inertia of torque transducer (from datasheet) & $2.66 \times 10^{-5} \mathrm{~kg} \cdot \mathrm{m}^{2}$ \\
Number of lines of encoder & 2048 \\
\hline \multicolumn{2}{c}{ Note: Nominal values are measured. }
\end{tabular}

Furthermore, it is found that at $\mathrm{C} 3$, the slope of the experimental result is almost the same as that of simulation result when the rotor speed is below 400rpm. This can be explained that the electromagnetic torque at $\mathrm{C} 3$ is almost ten times $\left(i_{a}=1 \mathrm{~A}\right)$ as large as those at $\mathrm{C} 1$ and $\mathrm{C} 2$, and the contribution of $J$ to $T_{e}$ will be relatively dominant compared with those of $F$ and static friction. Thus, the estimation error of $J$ by the Scheme 1 at $\mathrm{C} 1$ and $\mathrm{C} 2$ is much larger than that at $\mathrm{C} 3$, as shown in Table II. In reality, the Scheme 1 can be used for the approximate determination of $J$ if the contributions of $F \omega_{r}$ and static friction to $T_{e}(1 \mathrm{~d})$ are much smaller than that of $J$.

In order to achieve a higher accuracy, the influence of $F$ is taken into account in the Scheme 3 being compared below. For the proposed Scheme3, only three values such as $i_{q}\left(t_{0}\right), i_{q}\left(t_{p}\right)$, and $\omega_{p}$, are needed for the calculation of $J$ and $F$. In order to get the sampling sequence number corresponding to time points $t_{0}$ and $t_{p}$, a searching program is developed and introduced in Appendix A.

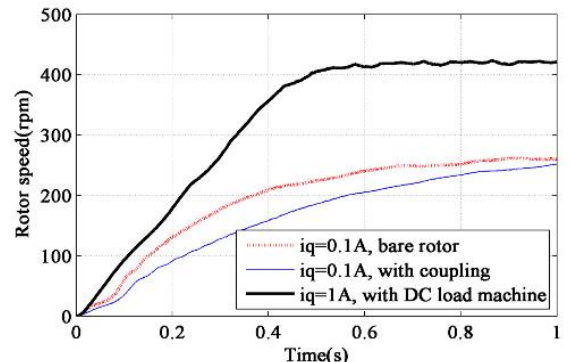

(a)

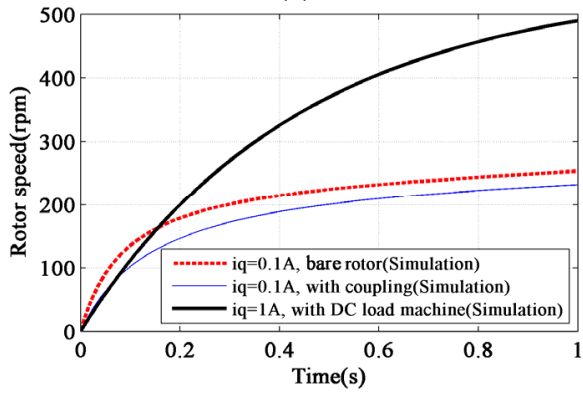

(b)

Fig. 4 Step response of rotor speed at different load conditions. (a) and (b) Experimentally measured and simulated step responses of rotor speeds.

Taking the measured signals shown in Fig. 5 as an example, the first zero crossing point of measured rotor speed is at $t=178 T_{s}=t_{0}$ and the second zero crossing point is at $t=378 T_{s}$. It is known that the sampling time $T_{s}$ is $0.0005 \mathrm{~s}$ and the period of $i_{q}$ and $\omega_{r}$ is set to $0.2 \mathrm{~s}$. Thus, the time length of a quarter of the period of $i_{q}$ and $\omega_{r}$ is $100 T_{s}$. In this case, the peak (or valley) value of rotor speed is at $t_{p}=t_{0}+100 T_{s}=278 T_{s}$, as shown in Fig. 5(a), and $i_{q}$ at $t=t_{0}$ and $t=t_{p}$ can be respectively indexed as shown in Fig. 5(b). Consequently, $J$ and $F$ can be calculated by substituting $\omega_{p}, i_{q}\left(t_{0}\right)$ and $i_{q}\left(t_{p}\right)$ to (7) and (9), respectively.

As mentioned in section II C, the Scheme 3 has one good feature that in theory, its determination of $J$ will not be influenced by $F \omega_{r}$ if the detection of zero crossing of rotor speed is ideal, as shown in (7). However, in reality, the speed measurement is always not ideal and the real rotor speed at the detected zero crossing point is usually not zero. Consequently, the influence of $F \omega_{r}$ will be not zero while the influence of static friction can be regarded as zero since $\omega_{r} \neq 0$. Thus, as can be seen from Tables III-V, assuming that $f$ is the frequency of perturbation signal, the influence of $f$ on the estimation of $J$ is dominant because the accuracy of detection of zero crossing of rotor speed at a fixed sampling rate $(2 \mathrm{kHz})$ will deteriorate if $f$ is getting too high, for example, $10 \mathrm{~Hz}$. In this case, a higher perturbation torque can be a good solution to mitigate this issue. For example, in Table $\mathrm{V}$, the estimation error at $\mathrm{C} 3$ is quite small (usually smaller than 3\%) compared with those in Table III and Table IV if $f=3 \mathrm{~Hz}$ or $f=5 \mathrm{~Hz}$. This can be explained that the amplitude of perturbation current is relatively high $(1.5 \mathrm{~A}$ and $2 \mathrm{~A}$ ) at $\mathrm{C} 3$ and the term $F \omega_{r}$ at the detected zero crossing point is quite small compared with the transient $T_{e}$. Thus, in order to ensure a higher ratio of signal versus noise, $f$ should be set to $f \leq 5 \mathrm{~Hz}$. Besides, since the system inertia is usually much larger than that of the rotor, the load condition C3 will be more typical in real applications. Thus, the Scheme 3 can achieve the accuracy of $<3 \%$ at $\mathrm{C} 3$ and obtain the result within one sinusoidal cycle of perturbation $(f=5 \mathrm{~Hz}, 0.2 \mathrm{~s})$, which is already fast enough for real applications. 


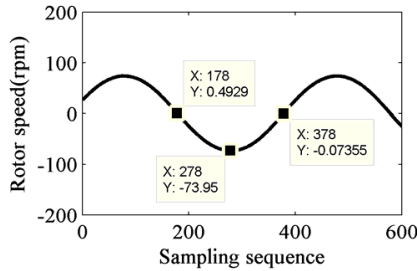

(a)

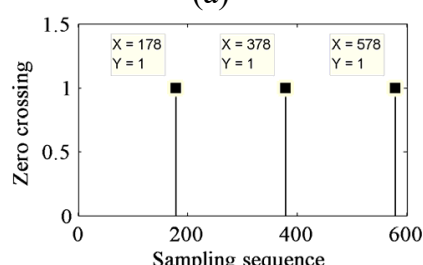

(c)

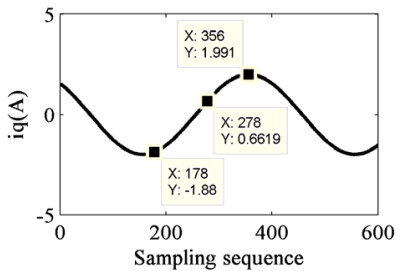

(b)

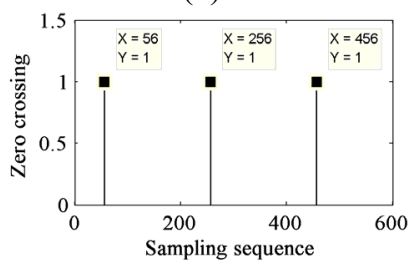

(d)
Fig. 5 Detections of zero crossing and peak value of perturbation signals while DC load machine is connected with PMSM rotor. (a) and (b) Measured rotor speed and $q$-axis current $(f=5 \mathrm{~Hz})$ with respect to sampling sequence. (c) and (d) Detected zero crossing of rotor speed and $q$-axis current.

TABLE II

RESULTS OF SCHEME1

\begin{tabular}{clll}
\hline \multirow{2}{*}{ Tests } & \multicolumn{2}{c}{ Combined moment of inertia $(J)$} & \multirow{2}{*}{ Error } \\
\cline { 2 - 3 } & Nominal values & Calculated results & \\
\hline $\mathrm{C} 1$ & $3.61 \times 10^{-4} \mathrm{~kg} \cdot \mathrm{m}^{2}$ & $1.60 \times 10^{-3} \mathrm{~kg} \cdot \mathrm{m}^{2}$ & $347.9 \%$ \\
$\mathrm{C} 2$ & $6.03 \times 10^{-4} \mathrm{~kg} \cdot \mathrm{m}^{2}$ & $2.30 \times 10^{-3} \mathrm{~kg} \cdot \mathrm{m}^{2}$ & $274.4 \%$ \\
$\mathrm{C} 3$ & $8.06 \times 10^{-3} \mathrm{~kg} \cdot \mathrm{m}^{2}$ & $1.06 \times 10^{-2} \mathrm{~kg} \cdot \mathrm{m}^{2}$ & $31.5 \%$ \\
\hline
\end{tabular}

TABLE III

RESULTS OF SCHEME3 AT C1

\begin{tabular}{cccccc}
\hline \multirow{2}{*}{$i_{q p}{ }^{*}$} & \multirow{2}{*}{$f$} & \multirow{2}{*}{$F$} & \multicolumn{3}{c}{ Combined moment of inertia $(J)$} \\
\cline { 4 - 6 } & & & Nominal values & Calculated results & Error \\
\hline $0.5 \mathrm{~A}$ & $3 \mathrm{~Hz}$ & $7.6 \times 10^{-4}$ & $3.61 \times 10^{-4} \mathrm{~kg} \cdot \mathrm{m}^{2}$ & $4.13 \times 10^{-4} \mathrm{~kg} \cdot \mathrm{m}^{2}$ & $14.4 \%$ \\
$0.5 \mathrm{~A}$ & $5 \mathrm{~Hz}$ & $2.1 \times 10^{-3}$ & $3.61 \times 10^{-4} \mathrm{~kg} \cdot \mathrm{m}^{2}$ & $4.37 \times 10^{-4} \mathrm{~kg} \cdot \mathrm{m}^{2}$ & $21.1 \%$ \\
$0.5 \mathrm{~A}$ & $10 \mathrm{~Hz}$ & $1.8 \times 10^{-2}$ & $3.61 \times 10^{-4} \mathrm{~kg} \cdot \mathrm{m}^{2}$ & $4.61 \times 10^{-4} \mathrm{~kg} \cdot \mathrm{m}^{2}$ & $27.7 \%$ \\
\hline
\end{tabular}

TABLE IV

RESULTS OF SCHEME3 AT C2

\begin{tabular}{cccccc}
\hline \multirow{2}{*}{$i_{q p}{ }^{*}$} & \multirow{2}{*}{$f$} & \multirow{2}{*}{$F$} & \multicolumn{3}{c}{ Combined moment of inertia $(J)$} \\
\cline { 4 - 6 } & & & Nominal values & Calculated results & Error \\
\hline $0.3 \mathrm{~A}$ & $3 \mathrm{~Hz}$ & $2.4 \times 10^{-3}$ & $6.03 \times 10^{-4} \mathrm{~kg} \cdot \mathrm{m}^{2}$ & $7.57 \times 10^{-4} \mathrm{~kg} \cdot \mathrm{m}^{2}$ & $25.5 \%$ \\
$0.5 \mathrm{~A}$ & $3 \mathrm{HZ}$ & $4.8 \times 10^{-4}$ & $6.03 \times 10^{-4} \mathrm{~kg} \cdot \mathrm{m}^{2}$ & $7.42 \times 10^{-4} \mathrm{~kg} \cdot \mathrm{m}^{2}$ & $23.1 \%$ \\
$0.3 \mathrm{~A}$ & $5 \mathrm{~Hz}$ & $1.8 \times 10^{-3}$ & $6.03 \times 10^{-4} \mathrm{~kg} \cdot \mathrm{m}^{2}$ & $7.59 \times 10^{-4} \mathrm{~kg} \cdot \mathrm{m}^{2}$ & $25.9 \%$ \\
$0.5 \mathrm{~A}$ & $5 \mathrm{~Hz}$ & $4.1 \times 10^{-3}$ & $6.03 \times 10^{-4} \mathrm{~kg} \cdot \mathrm{m}^{2}$ & $7.65 \times 10^{-4} \mathrm{~kg} \cdot \mathrm{m}^{2}$ & $26.9 \%$ \\
$0.5 \mathrm{~A}$ & $10 \mathrm{~Hz}$ & $3.6 \times 10^{-2}$ & $6.03 \times 10^{-4} \mathrm{~kg} \cdot \mathrm{m}^{2}$ & $8.06 \times 10^{-4} \mathrm{~kg} \cdot \mathrm{m}^{2}$ & $33.7 \%$ \\
\hline
\end{tabular}

TABLE V

RESULTS OF SCHEME3 AT C3

\begin{tabular}{cccccc}
\hline \multirow{2}{*}{$i_{q p}{ }^{*}$} & \multirow{2}{*}{$f$} & \multirow{2}{*}{$F$} & \multicolumn{3}{c}{ Combined moment of inertia $(J)$} \\
\cline { 4 - 6 } & & & Nominal values & Calculated results & Error \\
\hline $1.5 \mathrm{~A}$ & $3 \mathrm{~Hz}$ & $1.7 \times 10^{-2}$ & $8.06 \times 10^{-3} \mathrm{~kg} \cdot \mathrm{m}^{2}$ & $8.10 \times 10^{-3} \mathrm{~kg} \cdot \mathrm{m}^{2}$ & $0.5 \%$ \\
$2 \mathrm{~A}$ & $3 \mathrm{~Hz}$ & $2.3 \times 10^{-2}$ & $8.06 \times 10^{-3} \mathrm{~kg} \cdot \mathrm{m}^{2}$ & $7.90 \times 10^{-3} \mathrm{~kg} \cdot \mathrm{m}^{2}$ & $2.0 \%$ \\
$1.5 \mathrm{~A}$ & $5 \mathrm{~Hz}$ & $8.1 \times 10^{-2}$ & $8.06 \times 10^{-3} \mathrm{~kg} \cdot \mathrm{m}^{2}$ & $8.00 \times 10^{-3} \mathrm{~kg} \cdot \mathrm{m}^{2}$ & $0.7 \%$ \\
$2 \mathrm{~A}$ & $5 \mathrm{~Hz}$ & $9.1 \times 10^{-2}$ & $8.06 \times 10^{-3} \mathrm{~kg} \cdot \mathrm{m}^{2}$ & $8.20 \times 10^{-3} \mathrm{~kg} \cdot \mathrm{m}^{2}$ & $1.7 \%$ \\
$1.5 \mathrm{~A}$ & $10 \mathrm{~Hz}$ & 0.42 & $8.06 \times 10^{-3} \mathrm{~kg} \cdot \mathrm{m}^{2}$ & $1.09 \times 10^{-2} \mathrm{~kg} \cdot \mathrm{m}^{2}$ & $35.2 \%$ \\
$2 \mathrm{~A}$ & $10 \mathrm{~Hz}$ & 0.45 & $8.06 \times 10^{-3} \mathrm{~kg} \cdot \mathrm{m}^{2}$ & $1.24 \times 10^{-2} \mathrm{~kg} \cdot \mathrm{m}^{2}$ & $53.8 \%$ \\
\hline
\end{tabular}

Besides, compared with the results of Scheme1, as shown in Table II, the estimation error of Scheme 3 at $\mathrm{C} 1$ and $\mathrm{C} 2$ is much smaller than that of Scheme1. For example, the estimation error of Scheme1 is around $300 \%$ at $\mathrm{C} 1$ and $\mathrm{C} 2$ while that of Scheme 3 is lower than $34 \%$. More importantly, at the typical load condition $\mathrm{C} 3$, the estimation error of Scheme3 is smaller than $3 \%$ if $f \leq 5 \mathrm{~Hz}$ while that of Scheme1 is larger than $30 \%$.

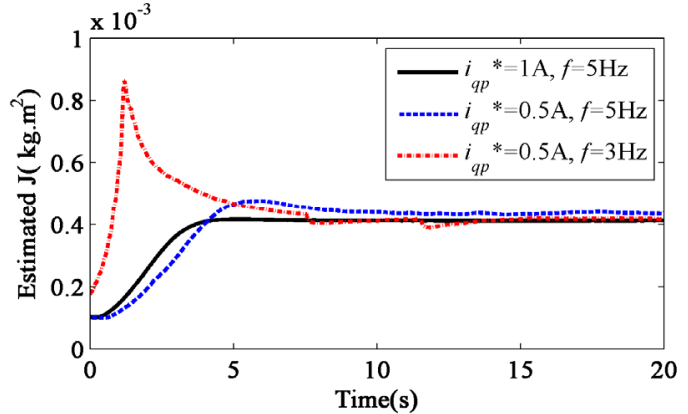

Fig. 6 Estimated moment of inertia of PMSM rotor by MRAS (scheme PI1: $\left.P_{J}=0.01, I_{J}=1000, P_{F}=1, I_{F}=1\right)$.

\section{B. Comparison between Scheme2 and Scheme3}

As introduced in section II, the Scheme2 also takes into account the influence of $F$ in its estimation model while the Scheme1 does not. In this case, the Scheme2 will be a better reference to the performance of the proposed Scheme3. In theory, a good MRAS based estimation of $J$ can be achieved if the estimated transient $\widetilde{\omega}_{r}$ can track the measured transient $\omega_{r}$. However, as can be seen from the expression of MRAS observers (3) and (4), the setup of PI constants of observers is quite important to ensure the tracking ability of algorithm since the input and output signals of observers are in the form of periodic forward-reverse perturbation. Figs. 6, 7 and Tables VI, VII are examples of applications of MRAS based $J$ observer using five different schemes (PI1-PI5) of PI constants and perturbation signals. As can be seen from Fig. 6, it is obvious that with the same PI constants (PI1), the convergence speed and final results of MRAS will be different under various perturbation schemes.

Furthermore, from Fig. 7, it is found that an improper setup of PI constants of MRAS observer will result in a divergence of estimation. Thus, it is essential that the setup of PI constants of MRAS observer should match the perturbation signal properly and consequently the tuning of PI constants becomes quite complex and usually depends on the expert experience. The proposed Scheme 3 does not have these issues and in theory, it can obtain $J$ within one sinusoidal cycle of perturbation, which is usually less than $0.5 \mathrm{~s}$ while the MRAS needs more than $1 \mathrm{~s}$ as shown in Fig. 6. Thus, the Scheme 3 is faster than the traditional MRAS in the determination of $J$. Furthermore, from the comparison between Tables III and VI, both the estimation errors of Scheme 3 and Scheme2 can achieve the accuracy of $15 \%-20 \%$ at the small load condition $\mathrm{C} 1$ if $f \leq 5 \mathrm{~Hz}$.

Besides, from the comparison between Tables IV and VII, both the estimation errors of Scheme 3 and Scheme 2 can be less than $3 \%$ at $\mathrm{C} 3$ if $f \leq 5 \mathrm{~Hz}$. This can be explained that both methods have taken into account the influence of $F$ and are based on the same reference/variable model (1d) while the measured data are of the same ratio of signal versus noise in both methods.

Thus, the accuracy of Scheme 3 is quite competitive to those conventional observer algorithm based methods such as the MRAS method (Scheme2), while it also has superior performances such as faster in calculation, lower computational cost and no need to tune the convergence speed to match the perturbation signal. 


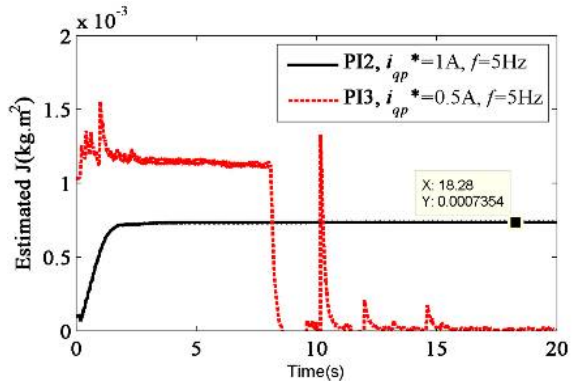

(a)

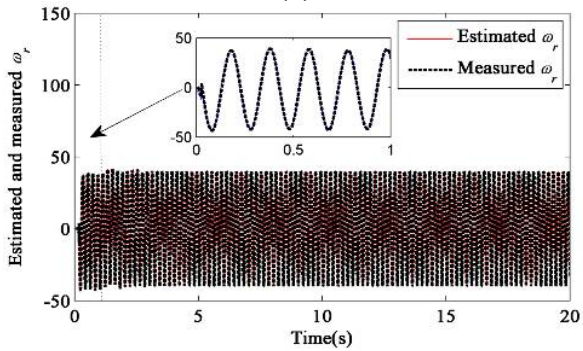

(b)

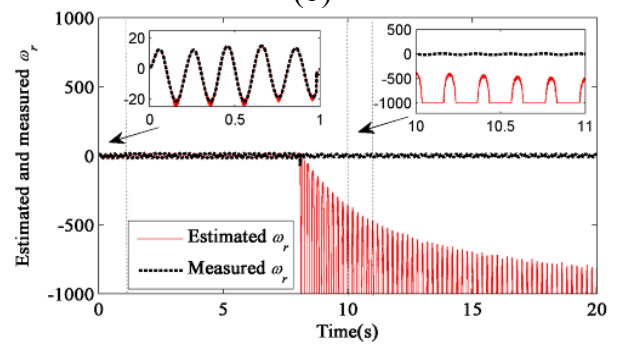

(c)

Fig. 7 MRAS based estimation of $J$ at C2. (a) Estimation of $J$ with two sets of different PI constants. (b) Estimated and measured $\omega_{r}$ with PI constants $P_{J}=1000, I_{J}=20000, P_{F}=10, I_{F}=100$ (scheme PI2). (c) Estimated and measured $\omega_{r}$ with PI constants $P_{J}=1000, I_{J}=1000, P_{F}=100, I_{F}=1000$ (scheme PI3).

TABLE VI

RESULTS OF MRAS BASED ESTIMATION AT C1

\begin{tabular}{cccccc}
\hline \multirow{2}{*}{$i_{q p}{ }^{*}$} & \multirow{2}{*}{$f$} & \multirow{2}{*}{ PI scheme } & \multicolumn{3}{c}{ Combined moment of inertia $(J)$} \\
\cline { 4 - 6 } & & Nominal values & Calculated results & Error \\
\hline $0.5 \mathrm{~A}$ & $3 \mathrm{~Hz}$ & PI1 & $3.61 \times 10^{-4} \mathrm{~kg} . \mathrm{m}^{2}$ & $4.19 \times 10^{-4} \mathrm{~kg} \cdot \mathrm{m}^{2}$ & $16.1 \%$ \\
$0.5 \mathrm{~A}$ & $5 \mathrm{~Hz}$ & PI1 & $3.61 \times 10^{-4} \mathrm{~kg} \cdot \mathrm{m}^{2}$ & $4.35 \times 10^{-4} \mathrm{~kg} \cdot \mathrm{m}^{2}$ & $20.5 \%$ \\
$1 \mathrm{~A}$ & $5 \mathrm{~Hz}$ & PI1 & $3.61 \times 10^{-4} \mathrm{~kg} . \mathrm{m}^{2}$ & $4.13 \times 10^{-4} \mathrm{~kg} \cdot \mathrm{m}^{2}$ & $14.4 \%$ \\
\hline
\end{tabular}

PI scheme PI1: $P_{J}=0.01, I_{J}=1000, P_{F}=1, I_{F}=1$.

TABLE VII

RESULTS OF MRAS BASED ESTIMATION AT C3

\begin{tabular}{cccccc}
\hline \multirow{2}{*}{$I_{q}^{*}$} & \multirow{2}{*}{ PI scheme } & \multicolumn{3}{c}{ Combined moment of inertia $(J)$} \\
\cline { 4 - 6 } & & & Nominal values & Calculated results & Error \\
\hline 2A & $3 \mathrm{~Hz}$ & PI5 & $8.06 \times 10^{-3} \mathrm{~kg} \cdot \mathrm{m}^{2}$ & $7.85 \times 10^{-3} \mathrm{~kg} \cdot \mathrm{m}^{2}$ & $2.6 \%$ \\
$2 \mathrm{~A}$ & $5 \mathrm{~Hz}$ & PI4 & $8.06 \times 10^{-3} \mathrm{~kg} \cdot \mathrm{m}^{2}$ & $8.18 \times 10^{-3} \mathrm{~kg} \cdot \mathrm{m}^{2}$ & $1.5 \%$ \\
$2 \mathrm{~A}$ & $5 \mathrm{~Hz}$ & $\mathrm{PI} 3$ & $8.06 \times 10^{-3} \mathrm{~kg} \cdot \mathrm{m}^{2}$ & $8.13 \times 10^{-3} \mathrm{~kg} \cdot \mathrm{m}^{2}$ & $0.9 \%$ \\
\hline \multicolumn{3}{c}{ PI scheme PI3: $P_{J}=1000, I_{J}=1000, P_{F}=100, I_{F}=1000}$. \\
PI scheme PI4: $P_{J}=100, I_{J}=100, P_{F}=10, I_{F}=100$. \\
PI scheme PI5: $P_{J}=1000, I_{J}=10000, P_{F}=1, I_{F}=1$.
\end{tabular}

\section{APPLICATION TO SPEED CONTROL}

\section{A. Design of PI Controller for Speed Loop}

Under $i_{d}=0$ control, the speed loop of a field oriented control system is illustrated in Fig. 8, in which the current loop $C_{i q}(\mathrm{~s})$ acts as an inner loop of the whole speed loop. In Fig. 8(a), $\omega_{r}{ }^{*}$, $T_{\omega}, K_{e}=1.5 p \psi_{m}, K_{n}$ and $K_{n i}=K_{n} / \tau_{n}$ are reference speed, time constant of low pass filter for measured rotor speed, torque

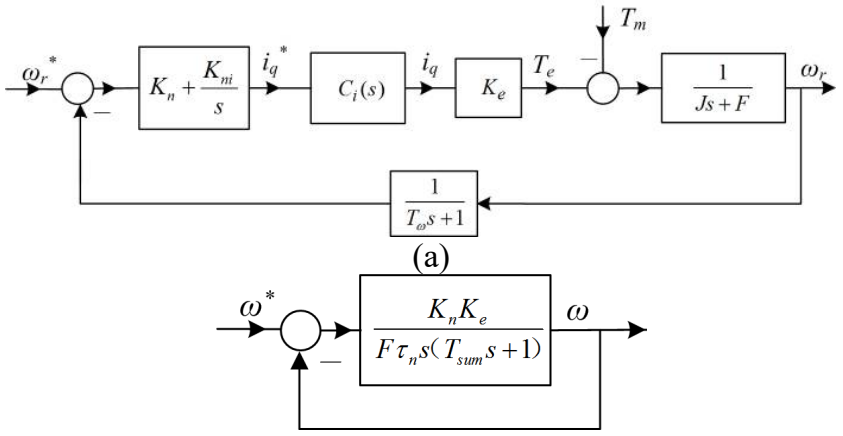

(b)

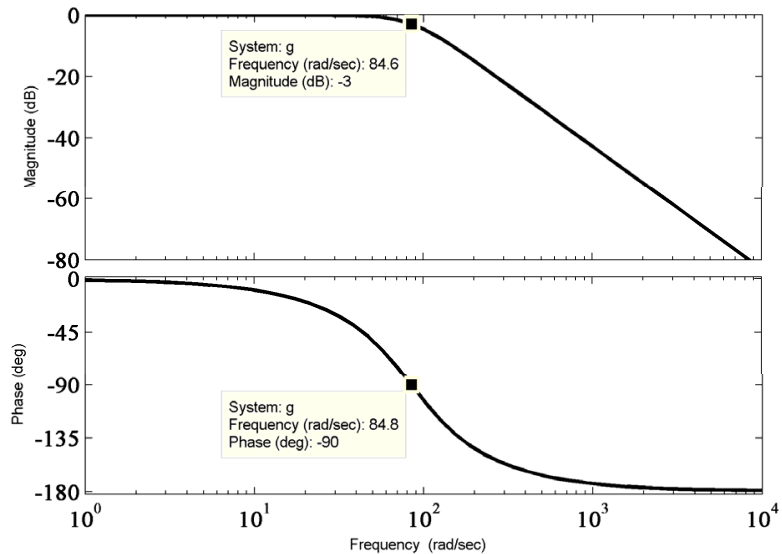

(c)

Fig. 8 Transfer function of speed loop of field oriented control. (a) Speed loop model. (b) Simplified speed loop. (c) Bode diagram of simplified speed loop. constant, PI constants of speed regulators. Since the time constant of current loop, $T_{s}$, and $T_{\omega}$ are usually much smaller than that of speed loop, a conventional solution to reduce the order of the drive system model is to combine those small time constants together and the simplified system transfer function can be expressed as Fig. 8(b) [20]. As introduced in [20], the optimized PI constants for speed loop can be expressed as:

$K_{n}=\frac{J}{2 K_{e} T_{\text {sum }}}$

$K_{n i}=\frac{K_{n}}{\tau_{n}}=\frac{F}{2 K_{e} T_{\text {sum }}}, \tau_{n}=\frac{J}{F}$

where $T_{\text {sum }}=T_{\omega}+2\left(T_{s}+T_{d}+T_{i f}\right)$, in which $T_{d}$ and $T_{i f}$ are the dead time of PWM control and low pass filter time constant of measured $d q$-axis currents [20]. The values of related small time constants are set to $T_{s}=1.0 \times 10^{-4} \mathrm{~s}, T_{\omega}=8.0 \times 10^{-3} \mathrm{~s}$, $T_{d}=6.0 \times 10^{-6} \mathrm{~s}$, and $T_{i f}=4.3 \times 10^{-5} \mathrm{~s}$, respectively. Besides, the PI regulators of $d q$-axis current loops can be obtained by substituting the nominal values of $L_{d}, L_{q}$, and $R$ to (13) and (14), respectively [20].

$K_{p d}=\frac{L_{d}}{2 T_{s f}}, K_{p q}=\frac{L_{q}}{2 T_{s f}}$

$K_{i}=\frac{R}{2 T_{s f}}$

where $T_{s f}=T_{s}+T_{d}+T_{i f}$ and $K_{p d}, K_{p q}$ and $K_{i}$ are PI constants of $d q$-axis current controllers. Thus, the derived PI constants of $d q$-axis current controllers are $K_{p d}=104.7, K_{p q}=196.3$, and $K_{i}$ $=20805$. 


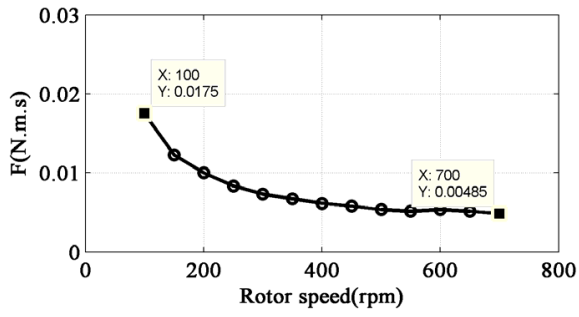

Fig. 9 Calculated $F\left(\omega_{r}\right)$ with respect different rotor speeds.

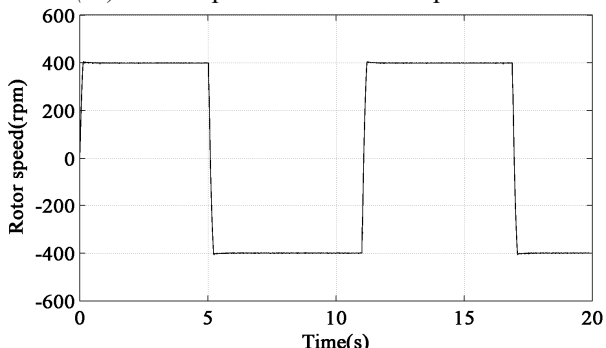

Fig. 10 Step response of rotor speed in forward and reverse directions.

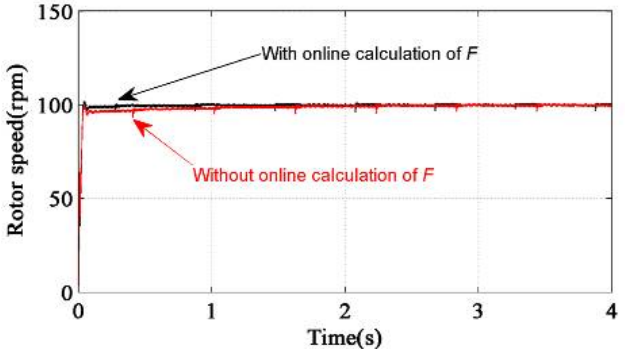

(a)

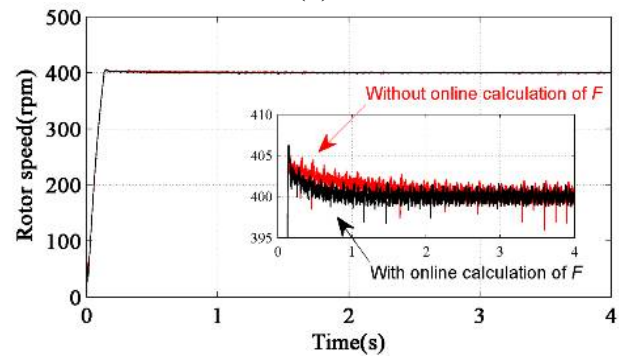

(b)

Fig. 11 Performance comparison between designed speed regulators with and without online calculation of $F\left(i_{d}=0, i_{q}=2.5 \mathrm{~A}\right)$. (a) Comparison at relatively low speed region. (b) Comparison at relatively high speed region.

For the determination of $F$ at different rotor speeds, the proportional constant of the speed regulator is derived by (11) using the average value $\left(8.05 \times 10^{-3} \mathrm{~kg} \cdot \mathrm{m}^{2}\right)$ of calculated $J$ (at $f=5 \mathrm{~Hz}$ and $3 \mathrm{~Hz}$ ) as shown in Table $\mathrm{V}$ while the integral constant is set to 0.1 . The curve of calculated $F$ by (10) is depicted in Fig. 9, which is then approximated by $F\left(\omega_{r}\right)=a \omega_{r}+b$, as introduced in Appendix B. $F\left(\omega_{r}\right)=a \omega_{r}+b$ will be then used to aid the online derivation of the integral constant by (12), as shown in Fig. 3(b). With the determined $J$ and average value of $F$, the bode diagram of the simplified speed loop as shown in Fig. 8(b) is then depicted in Fig. 8(c), which shows that the bandwidth of speed loop at $\mathrm{C} 3$ is $84.6 \mathrm{rad} / \mathrm{s}$.

\section{B. Performance Tests of Designed PI Controllers}

The performance of speed PI regulator derived by (11) and (12) is then tested and shown in Fig. 10, in which the proportional constant is derived by using the average value of calculated $J$ and the integral constant is derived by using the

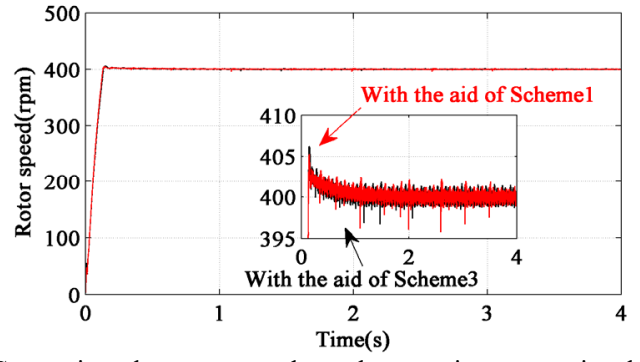

Fig. 12 Comparison between speed regulators using proportional constants derived with aids from Scheme 1 and Scheme3 $\left(i_{d}=0, i_{q}=2.5 \mathrm{~A}\right)$, respectively.

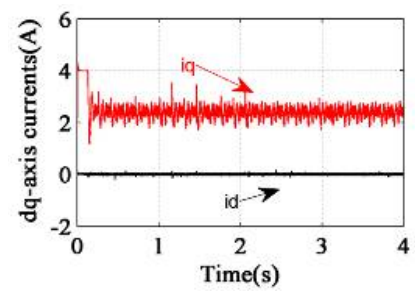

(a)

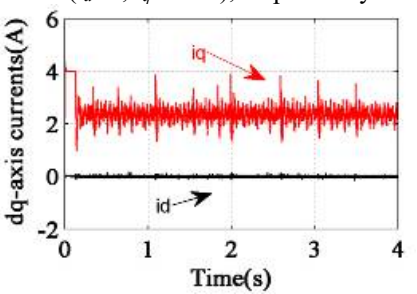

(b)
Fig. $13 \mathrm{D} q$-axis currents in tests shown in Fig. 12(b) $\left(i_{d}=0, i_{q}=2.5 \mathrm{~A}\right)$. (a) Speed regulator using proportional constant derived with aids from Scheme3. (b) Speed regulator using proportional constant derived with aids from Scheme1. real-time calculated $F\left(\omega_{r}\right)=a \omega_{r}+b$, as shown in Fig. 3(b). It is obvious that the PMSM can rotate in the forward and reverse directions with quite small overshoot and short settling time. Fig. 11 shows the performance comparison between two speed regulators using PI constants derived with and without online calculation of $F\left(\omega_{r}\right)=a \omega_{r}+b$. The speed regulator without online calculation of $F\left(\omega_{r}\right)$ uses the average value of calculated $F$, as shown in Fig. 9, to derive the integral constant by (12).

From the comparison results at relatively low and high speeds, it is found that the speed regulator with the online calculation of $F$ shows better performance in eliminating the steady state error. This can be explained that since $F$ decreases with the rotor speed, the derived integral constant by using the average value of $F$ will be too small at low speed region while it will be too big at high speed region. In this case, the scheme using online calculated $F\left(\omega_{r}\right)$ with respect to the transient rotor speed, as shown in Fig. 3(b), will be superior in improving the performance of speed regulator at different rotor speeds.

Figs. 12 and 13 are the performance comparison between two speed regulators using two different proportional constants, of which both the integral constants are online tuned with the real-time calculated $F$ with respect to the transient rotor speed, as shown in Fig. 3(b). It is found that $i_{q}$ of both tests will reach the maximum limit (4A) immediately at the beginning of step response, as shown in Fig. 13, which will result in a similar step response of rotor speed, as shown in Fig. 12. However, at the steady state, the speed regulator using the calculated $J$ by Scheme3 shows better dynamic performance in $i_{q}$. This can be explained that the calculated $J$ by Scheme 1 is $31.7 \%$ larger than that of Scheme3, which will result in a bigger peak-to-peak ripple in the $q$-axis current.

Thus, it is confirmed that the identified $J$ by Scheme 1 can also be employed for the design of speed loop regulator although the dynamic performance can be further improved if the identified $J$ by Scheme3 is employed. In reality, both methods can be good alternatives for the fast determination of $J$. 


\section{CONCLUSION}

A method for fast determination of combined moment of inertia of PMSM drive system is proposed in this paper. It is based on the addition of sinusoidal perturbation to the drive system and the combined moment of inertia can be accurately identified while the influence of viscous friction has been eliminated during the modeling process. Its accuracy is higher than the conventional method without taking into account the influence of viscous friction and is also competitive to the conventional MRAS based observer. More importantly, compared with the MRAS, the proposed method is superior in faster determination, easier implementation, and lower computational cost. Besides, the application of estimated mechanical parameters in the design of speed loop PI regulator is also investigated while a good performance is achieved.

\section{APPENDIX A}

The fake code for zero crossing detection is shown below, in which variables such as Data, Polarity, and ZeroCrossing are measured raw data such as $i_{q}$ and rotor speed, polarity of measured data, and sequence number of zero crossing point of measured raw data, respectively.

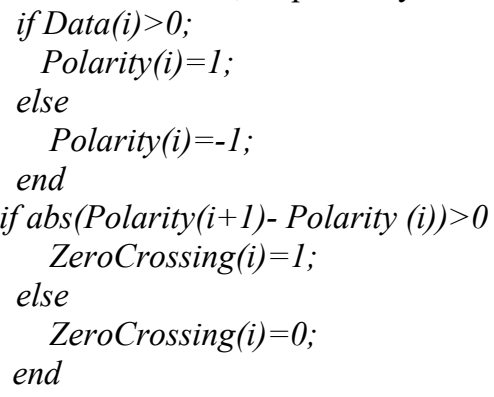

\section{APPENDIX B}

In this paper, $F\left(\omega_{r}\right)$ is curve fitted by a linear function (B.1). $f(x)=a x+b$

where $x$ is the measured transient $\omega_{r}$ and $f(x)$ is the calculated $F\left(\omega_{r}\right)$. The reason why the linear function (B.1) is employed as the curve fit function is that it only needs to measure two points to derive the values of $a$ and $b$.

\section{REFERENCES}

[1] N.J. Kim, H.S. Moon, and D.S. Hyun "Inertia identification for the speed observer of the low speed control of induction machines," IEEE Trans. Ind. Applicat., vol. 32, no. 6, pp. 1371 -1379, Nov./Dec. 1996.

[2] F.J. Lin, and H.M. Su, "A high-performance induction motor drive with on-line rotor time-constant estimation," IEEE Trans. Energy Convers., vol. 12, no. 4, pp. 297 -303, Dec. 1997.

[3] S.M. Yang, and J.D. Lin, "Observer-based automatic control loop tuning for servo motor drives," in Proc. IEEE 10th International Conference on Power Electronics and Drive Systems (PEDS), 2013, pp.302-305.

[4] J.W. Choi, S.C. Lee, and H.G. Kim, "Inertia identification algorithm for high-performance speed control of electric motors," IEE-Proc. Power Applicat., vol. 153, no. 3, pp. 379-386, May 2006.

[5] F. Andoh, "Moment of inertia identification using the time average of the product of torque reference input and motor position," IEEE Trans. Power Electron., vol. 22, no. 6, pp. 2534-2542, Nov. 2007.

[6] I. Awaya, Y. Kato, I. Miyake, and M. Ito, "New motion control with inertia identification function using disturbance observer," in Proc. International Conference on Power Electronics and Motion Control, 1992, pp.77-81.
[7] Y.J. Guo, L.P. Huang, and M. Muramatsu, "Research on inertia identification and auto-tuning of speed controller for AC servo system," in Proc. Power Conversion Conference, 2002, vol. 2, pp. 896-901.

[8] S.J. Hong, H.W. Kim, and S.K. Sul, "A novel inertia identification method for speed control of electric machine," in Proc. IECON, 1996, pp. 1234-1239.

[9] R. Babau, I. Boldea, T.J.E. Miller, and N. Muntean, "Complete parameter identification of large induction machines from no-load acceleration-deceleration tests," IEEE Trans. Ind. Electron., vol. 54, no. 4 pp. 1962-1972, Aug. 2007.

[10] Y. Feng, X.H. Yu, and F.L. Han, "High-order terminal sliding-mode observer for parameter estimation of a permanent-magnet synchronous motor," IEEE Trans. Ind. Electron., vol. 60, no. 10, pp. 4272-4280, Oct. 2013.

[11] G.S. Buja, R. Menis, and M.I. Valla, "Disturbance torque estimation in a sensorless DC drive," IEEE Trans. Ind. Electron., vol. 42, no. 4, pp. 351-357, Aug. 1995.

[12] R. Garrido, and A. Concha, "Inertia and friction estimation of a velocity-controlled servo using position measurements," IEEE Trans. Ind. Electron., vol. 61, no. 9, pp. 4759-4770, Sep. 2014.

[13] K.H. Kim, and M.J. Youn, "A nonlinear speed control for a PM synchronous motor using a simple disturbance estimation technique," IEEE Trans. Ind. Electron., vol. 49, no. 3, pp. 524-535, Jun. 2002.

[14] F.J. Lin, "Robust speed-controlled induction-motor drive using EKF and RLS estimators," IEE Proc.-Electr. Power Applicat., vol. 143, no. 3, pp. 186 -192, May 1996.

[15] J.S. Ko, J.H. Lee, and M.J. Youn, "Robust digital position control of brushless DC motor with adaptive load torque observer," IEE Proc.-Electr. Power Applicat., vol. 141, no. 2, pp. 4759-4770, Mar. 1994.

[16] S.W. Wang, and S.M. Wan, "Estimation of load parameters for PMSM by MRAS," in Proc. IEEE International Conf. Electrical and Control Engineering, 2011, pp. 657-660.

[17] K. Liu, and Z.Q. Zhu, "Mechanical parameter estimation of permanent-magnet synchronous machines with aiding from estimation of rotor PM flux linkage," IEEE Trans. Ind. Applicat., vol. 51, no. 4, pp. 3115-3125, Jul./Aug. 2015.

[18] S.H. Li, and Z.G. Liu, "Adaptive speed control for permanent-magnet synchronous motor system with variations of load inertia," IEEE Trans. Ind. Electron., vol. 56, no. 8, pp. 3050-3059, Aug. 2009.

[19] T. Senjyu, K. Kinjo, N. Urasaki, and K. Uezato, "Parameter measurement for PMSM using adaptive identification," in Proc. IEEE Int. Symp. Ind. Electron., May 2002, vol. 3, pp. 711-716.

[20] K. Liu, and Z.Q. Zhu, "Parameter estimation of PMSM for aiding PI regulator design of field oriented control," in Proc. ICEMS, 2014, pp. 2705-2711.

[21] X. W. Wang, and J. Yi, "Identification of AC servo system," China Patent CN101231207 A, Jan. 30, 2008.

[22] G. Zhang, and J. Furusho, "Speed control of two-inertia system by PI/PID control," IEEE Trans. Ind. Electron., vol. 47, no. 3, pp. 603-609, Jun. 2000.

[23] K.R. Shouse, and D.G. Taylor, "A digital self-tuning tracking controller for permanent-magnet synchronous motors," IEEE Trans. Contr. Syst. Tech., vol. 2, no. 4, pp. 412-422, Dec. 1994.

[24] A.J. Blauch, M. Bodson, and J. Chiasson, "High-speed parameter estimation of stepper motors," IEEE Trans. Contr. Syst. Tech., vol. 1, no. 4, pp. 270-279, Dec. 1993.

[25] Y.H. Kim, and I.J. Ha, "A learning approach to precision speed control of servomotors and its application to a VCR," IEEE Trans. Contr. Syst. Tech., vol. 7, no. 4, pp. 466-477, Jul. 1999.

[26] D. Basic, F. Malrait, and P. Rouchon, "Current Controller for low-frequency signal injection and rotor flux position tracking at low speeds," IEEE Trans. Ind. Electron., vol. 58, no. 9, pp. 4010-4022, Sep. 2011.

[27] R. Mizutani, T. Takeshita, and N. Matsui, "Current model-based sensorless drives of salient-pole PMSM at low speed and standstill," IEEE Trans. Ind. Applicat., vol. 34, no. 4, pp. 841-846, Jul./Aug. 1998.

[28] Y. Yu, Z. Mi, X. Guo, Y. Xu and T. Zhao, "Low speed control and implementation of permanent magnet synchronous motor for mechanical elastic energy storage device with simultaneous variations of inertia and torque," IET Electric Power Applicat., vol. 10, no. 3, pp. 172-180, Jul. 2016. 